\title{
Making room for grief: walking backwards and living forward
}

Nancy J. Moules, Karl Simonson, Mark Prins, Paula Angus and Janice M. Bell Faculty of Nursing, University of Calgary, Calgary, Alberta, Canada

Making room for grief: walking backwards and living forward In this paper, the authors describe an aspect of a program of research around grief and clinical practice. The first phase of the study involves examination of experiences of grief with attention to troublesome or problematic beliefs that fuel the extent of suffering in the bereaved. The data, obtained from a review of videotaped clinical interviews with families seen in the Family Nursing Unit at the University of Calgary were analyzed according to philosophical hermeneutic tradition. Findings suggest that grief is an experience that is ongoing, that changes in nature over time, but that involves a continuing relationship with the deceased; it is a graceful, periodic, deliberate walk backwards while keeping a sure foot in living forward.

\section{Key words: beliefs, bereavement, grief, loss.}

Making room for grief is not a popular concept. In the past 100 years, attention has been placed on models of practice around grief that involve assisting people to let go of grief and symbolically and emotionally to let go of the lost person. This paradigm and widely accepted model of grief therapy is inherently based on a modernist tradition, and grief research has, until recently, been grounded in quantitative assessment that supports this worldview (Silverman 1996). A changing perspective of grief as an ongoing experience that is not resolvable, but is imminently livable is emerging in the literature (Attig 1996; Klass, Silverman and Nickman 1996; Moules 1998; Moules and Amundson 1997; Neimeyer 2001, 2003). The bereaved themselves, however, suggest that the general public continue to be influenced by prevailing modernist beliefs. Discourses that suggest that successful recovery from grief involves an absence of feelings of grief and the achievement of relinquished emotional connections with the deceased, continue to create problems that increase suffering in the bereaved. This suffering shows itself in the internalization of beliefs that constrain, confine, and pathologize the experience of grief.

In clinical practice with the bereaved, it is apparent that there are commonly held beliefs which contribute to the amount and nature of their suffering in grief. These beliefs are perpetuated through popular literature, culture, and the nature of some therapeutic practices. Yet, experiences of grief contradict these culturally sanctioned theories, and this very contradiction can inadvertently create a sense of failure, incompetence, and even pathology, thereby leading to even more suffering in the lives and relationships of those who find themselves in the universal situation of loss. 


\section{WHY DO BELIEFS MATTER? CONTEXT FOR RESEARCH}

The data for this component of the study were obtained from a review of videotapes of clinical sessions with families experiencing grief. The videotapes were accessed through the Family Nursing Unit (FNU) at the University of Calgary, Alberta, Canada. The FNU is an outpatient educational and research clinic that was created by Dr Lorraine M. Wright in 1982 as a means to provide a teaching facility and context that affords the opportunity of live clinical supervision for graduate nursing students in Family Systems Nursing. Further; it is a research unit that has demonstrated over 20 years of research around families, illness, suffering, and intervention. In the course of teaching and research the unit offers support to families experiencing suffering in their lives and relationships as a result of serious illness or life events.

The practice model utilized and taught in the FNU, under the current direction of Dr Janice M. Bell, is a model for advanced nursing practice that developed out of research of clinical work in the FNU. This model is called the Illness Beliefs Model (Wright, Watson and Bell 1996) and at the core of the model is the philosophical assumption that it is not the problems or illnesses themselves but the beliefs that people hold about these that are the problem. In the uncovering of problematic beliefs around many areas such as etiology, diagnosis, prognosis. spirituality, role of family members and health care professionals, mastery and control, sources of suffering can be determined and the nurse clinicians can then work collaboratively with the family to challenge problematic or constraining beliefs and to rein force facilitating ones (Wright, Watson and Bell 1996). Because of the focus of this clinical work being directed toward beliefs, the clinical work of the FNU provided rich archival data for uncovering specific beliefs about the experience of grief.

\section{PHILOSOPHICAL ASSUMPTIONS AND BELIEFS OF THE RESEARCHERS}

The researchers entered into this project holding their own beliefs about grief, thus providing a philosophical foundation for the work. Grief was accepted as a lifelong and life- changing experience. Arnold (1995) described grief as a human experience that has received inadequate conceptualization in nursing literature. Arnold reconceptualized grief as a continuous life process. The idea of grief as a lifelong experience has not been the prevalent one in grief theory or in popularized literature, but it is a conceptualization that is emerging and has a profound influence on the ways in which health professionals can be helpful to those who are bereaved (Moules 1998; Rosenblatt 1996).

Moules (1998) suggested that some individuals find ways to live through the sorrow that accompanies grief, and ignore the implication that they must give up and 'get over' their grief in a timely fashion. They are able to find ways to privately make room for their grief that is not subject to public scrutiny and criticism. Other people, however, seem to come to impasses in their experiences of loss where their grief continues to subsume them with suffering and invites them into lifestyles that are characterized by continued efforts to end grief and 
subsequent experiences of failure to do so. This sense of failure and incompetence is fueled by a cultural discourse that suggests that not only is grief 'resolution' possible, but expected and normal. Evidence of the way that society and the healthcare system has pathologized grief lies in the plethora of terms that have emerged in both conceptual and clinical work with the bereaved, terms such as 'abnormal, complicated, pathological, unresolved, chronic, morbid, prolonged, dysfunctional, or exaggerated' grief (Jacob 1993; Rancour 1998; Kaunonen et al. 2000; Schut et al. 2001). Traditionally, therapy or clinical intervention with the bereaved has focused around helping people continue to find a way to end their grief (Becvar 2001; Wortman 2001).

The word 'grief' is defined as sorrow and the emotional suffering caused by loss (Neufeldt and Guralnik 1988). A more useful understanding of grief lies in the assumption that grief is larger than sorrow. Sorrow is an overwhelming sadness, an emotion that is contained within grief, but grief is as much the celebration of the lost person as it is the relinquishing or sorrowing in loss. Within grief, there are aspects of intense sadness, but intense sadness over loss can end, yet grief remains and is experienced again and again over time. In many ways, one could argue that loss becomes a part of our biological structure in the shape of grief (Maturana and Varela 1992; Goodkin et al. 2001). Grief is a biological experience (Sacks 2001) as well as an emotional, spiritual, and cognitive one. As a result, grief becomes an enduring, some times relenting, sometimes poignant, but always present part of the life of a person who has lost.

The visibility of grief to society's gaze is when grief becomes problematic, because the tolerance of such visibility is limited (Averill and Nunley 1988; Arnold 1995; Solari-Twadell et al. 1995). There is a cultural notion that people should get over a loss and not continue to feel grief (Rosenblatt 1996). As a result, people learn to establish a relationship with grief that is private and not open to public scrutiny. Within this clandestine relationship, people can be invited into pathologizing themselves as abnormal for continuing to feel grief, and this selfdiagnosis may sponsor stories of incompetence, withdrawal, depression, or isolation (Moules and Amundson 1997). At this point, people may become conscripted into cultural descriptions of dysfunction and seek out clinical intervention. Within clinical intervention, many disciplines, including nursing, continue to support the discourse that the treatment of grief is to eliminate it (Arnold 1995; Sharpnack 2001; Wortman and Silver 2001).

It is our belief that effective nursing needs to allow for the ultimate outcome of clinical work not to be 'getting over', resolving, or ending grief, but finding a way through suffering and sorrow to make room for a relationship with grief that is livable, acceptable, creative, and for a life that may even be richer for its presence (Moules 1998). Grief needs to be reclaimed into life, families, and nursing (Rycroft and Perlesz 2001). As a part of this practice of making room for grief, an understanding of the beliefs that have been internalized within the bereaved is a critical understanding. 


\section{METHOD, DATA COLLECTION, AND ANALYSIS}

This research project is a hermeneutic interpretive study, based on the philosophy of Hans Georg Gadamer (1989). Hermeneutics is the tradition, theory, and practice of interpretation and understanding in human contexts. Grief is an interpreted experience and nursing is interpretive. As nurses, we are situated in the middle of understanding, and understanding is necessarily connected to interpretation. The kinds of discretions that are called forth in nursing are about making sense of particulars, putting them in context, assigning relevance and meaning, and acting on the implications of that meaning. In nursing, there is no such thing as an un-interpreted observation and, as such, nurses are brokers of understanding. Conversational encounters with grief are about understanding and interpretation.

Hermeneutic inquiry involves the selection of participants or exemplars of practice that can best illuminate the topic and invite an extended understanding of it. In this study, the clinical work with six families seen at the FNU, who presented with concerns around loss and grief, was selected for this research. This did not involve an active recruitment of participants, but rather a selection of existing data in the form of videotaped clinical sessions. Clients seen in the FNU sign a consent form for videotaping of the clinical session to be used for purposes of education and/or research. In the cases of the chosen exemplars, all clients signed consent for the purposes of both education and research. Further to this consent, the research was granted ethical approval through the Conjoint Health Research Ethics Board of the Faculties of Medicine, Nursing and Kinesiology, University of Calgary, Canada. Although this research was not intended to focus on the families themselves as participants, but rather on the beliefs that surfaced in the sessions, some demographic information is important to consider. The clinical work with each family varied from three to five sessions. The family members included a total of nine members, five women and four men. Losses incurred included the loss of children, ranging from infant to young adult, and loss of spouses. The time since the losses varied from 3 months to 5 years. All family members were white people.

The videotapes were reviewed for extraction of beliefs that seemed linked to grief, and which may have been potentially diminishing or contributing to the suffering associated with grief. The data were then transcribed to text. Analysis, in the hermeneutic tradition, is synonymous with interpretation. The process of analysis in this study involved individual team members' thorough reading of the textual data and subsequent writing of interpretive memos. Research team meetings were then organized around arriving at a collective hermeneutic understanding of the beliefs. The meetings were audiotaped, transcribed to text, and became further data for analysis. The final stage of analysis involved interpretive writing, with an emphasis on practical applications of the findings. 


\section{FINDINGS}

\section{Belief grief is about saying goodbye}

'I took off my rings and put them away.' This action, expressed by a woman who lost her husband, exemplifies the belief that severing connections to the deceased is what one is supposed to do. This is a popular belief that has its roots in nearly 100 years of theory and practice. Freud (1947) defined mourning as early as 1917 as the process of energy withdrawal and libido detachment from the lost object, therefore freeing and un-inhibiting the ego. Despite the fact that Freud's own personal experiences of grief and loss defied his theory (Silverman and Mass 1996), the ideas of severing bonds and forming new attachments has stubbornly tethered itself to many grief models. The area of death study, known as 'Thanatology' comes from the personified Greek god, Thanatos, who represented death. Freud maintained that suffering lay in the human struggle between a desire for union, or Eros, and the desire for separation, Thanatos. Alternately, Silverman and Klass (1996) suggested that successful 'resolution' of grief lies not in letting go, but in internalizing and incorporating aspects of the lost person, such that an external presence is no longer necessary. This idea, however, was not until quite recently widely taken up by the therapeutic community and not adopted by general popular discourse.

Yet, despite dominant theory and cultural expectations, the idea of loss as disconnection is contradicted in the experience of loss. As expressed by one family member in the study. 'When my grandmother died, I thought I would lose her, but I didn't - I become more like her every day, so I did not lose her at all.' This particular belief was revealed only after an inquiry was made into her initially expressed belief that death meant loss of the person. The client expressed this first belief in a way that implied her anticipation of the expectation that she needed to put her rings away and forget her husband, forgetting her other life experience of the loss of her grandmother, where she did, in fact experience continuing to be in relationship with her grandmother after she died. In this remembering of something that was forgotten, a new and healing belief emerged.

Why was this person unable to apply what she had learned in the past to her current situation? Does pain blind oneself to the availability of reflection in the moment? Perhaps optimum reflection is a luxury that can be had only when one is not blinded by things that take over in life. On the other hand, it might be suggested that the legacy of Freud lives on and is deeply embedded in a cultural discourse that continues to invite the bereaved into believing that grief is the work of saying goodbye and severing connections, rather than finding new relationships with other dimensions and depths.

The statement made by another woman who lost her son to suicide was, 'I'm losing my memory of him.' This statement suggests that a part of grief's function is to help keep the memory going and the connection in place.

Another belief expressed I a bereaved young woman who lost both her brother and father within a year beautifully speaks to the experience that relationships do continue. This woman stated: 
When you lose somebody it's almost like you're building a house and when somebody dies, all the top gets taken off but the foundation is still there. This is how I picture it. So we still have this foundation but we have to build it up again and in that foundation are my dad and brother - still there. They're still there. And they're so much engrained in who we are but all of the physical manifestations of them are gone.

Shifts in our understandings of grief not as saying good bye but continuing in relationship are beginning to emerge in the literature and are shaping new understandings of grief and models of practice (White 1989; Klass, Silverman and Nickman 1996; Moules 1998). Often such conceptual, theoretical, and even paradigmatic shifts, however, precede the public's perception, and deeply entrenched, previously held understandings of grief continue to contribute to an old discourse.

\section{Belief there is a right way to grieve that involves the resolution of grief as measured by its absence}

The bereaved clients in this study often held a 'core belief' (Wright, Watson and Bell 1996) that they did not think they were 'doing this grieving thing right'. Comments such as 'I don't know how to get over it; I don't know how much to show' suggest that people are sensitive to the gaze of others and that their feelings are not legitimate and therefore need to be kept hidden. It follows then that if grief is something to be resolved and if resolution is equated to the absence of feelings of grief, then the enduring presence of grief is an indication that there is something wrong with the bereaved. This evaluation can take the form of self-criticality, external assessment, and even pathologizing of the continuing presence of grief. Grief seemed to be considered an indulgence that is not appropriate.

Another belief that emerged is the idea that to talk about the sadness means to fall apart, to give grief voice and space would make it worse. This belief seems to be fed by the cultural discourse that a visible grief is an unhealthy grief and to make room for grief would be allowing it take over altogether.

'I don't think we'll ever get over it.' This statement was made with a confessional tone, as though in apology that they could not seem to accomplish what they believed was supposed to occur in grieving. This belief expresses the experience of grief persisting, despite the fact that somehow they believe they should be able to get over it.

Is resolution of deep grief possible? We suspect that the answer lies in how the word resolution is understood. Some definitions of resolution are to change or transform some thing; to solve a puzzle; or to blend something together to bring clarity and vision (Agnes and Guralnik 1999). These definitions of resolution seem to fit with grief However, when resolution is understood as the ending of something, or to cause it to subside or disappear (Agnes and Guralnik 1999), it becomes a troublesome belief to hold and live up to. Unfortunately, this is the shape that resolution has taken in the way it is most commonly regarded 
both in therapeutic communities and in general cultural discourse. When resolution is understood as the ending of something and when it is evaluated by the evidence of the absence of feelings of grief, then, as grief persists over time, people are subjected to a continual reminder they are not able to complete the process in a competent

One family in this study was asked by the nurse in the clinical session videotape what questions they most asked themselves and their responses to this question were: 'Will we have good times again?' 'Will our future always be tainted?' The nurse embraced these question, talked about the idea that resolution may not be possible if you consider it as the absence of grief, but that there are other aspects to grief that are not all about suffering. Therefore, they will have good times again. Grief does not get in the way of ever experiencing happiness again. Futures do not need to be tainted.

Some families in the videotapes seemed to listen to an inner wisdom that defied cultural instructions to get over loss. One woman made the observation about her family's experience of her son's death: we need steps to get on with life, not over him ... we're never going to get over his death, we don't want to get over him.' The research suggests an extension of the shifting tide of grief theory that supports the importance of understanding the work of grief to involve maintaining connection and relationship with the lost other. We suggest, however, that embedded in this new theory there is some implication that a new relationship with the deceased that is well-developed and maintained will result in the resolution of grief, not in the sense of bringing it to clarity but of its ending. Our research offers the idea that grief does not need to disappear to resolve, that in fact its very presence is what serves to help maintain this relationship. What needs to be challenged here is the definition of grief as only sorrowful, as opposed to the poignant, important reminder of the lost person. There is some grief that is comforting. 'I need to feel it at times; I miss it when I don't. It helps.'

Silverman and Klass (1996) wrote:

We cannot look at bereavement as a psychological state that ends and from which one recovers. The intensity of feelings may lessen ...

however, a concept of closure, requiring a determination of when the bereavement process ends, does not seem compatible with the model suggested by these findings. We propose that rather than emphasizing letting go, the emphasis should be on negotiating and renegotiating the meaning of the loss over time (18-19).

The regard of grief as a meaning-making activity, as well as an emotional one, contextualizes grief in cognitive, affectual, spiritual, and social domains.

\section{Belief grief involves moving on}

'We don't know how to go forward; my heart is in so much pain.' Several beliefs that were uncovered in this study presented the theme of moving ahead. There is a disquieting paradox in this notion of movement. Grief is about navigating a way to move on with life, but it is also about a draw to remain in the past. C. S. Lewis 1961) suggested that grief is about writing a history rather than drawing a map. 
Grief invites us to look back, to remember. We willingly and necessarily, in grief, walk back into time and history, recalling when the one who died was physically present. At the same time, however, we learn how to continue to live and to move ahead. This is a map-less journey, for grief takes its own shape for each person (although stage model theories of grief would have us believe otherwise). Perhaps people run into difficulties in this journey when they believe that they must stop looking back in order to move ahead.

In this regard, our Western culture might take lessons from Eastern traditions that value the art of 'walking backwards'. This physical movement of literally moving ahead while facing backwards developed out of a tradition based on exercise but grounded in philosophy. China's ancient Mountain and Sea scripture records the itinerant immortal who $\|$ backward faster than the eye could see. Walking backwards has been popular ever since and it is not uncommon to see a Chinese person (particularly an older person) engaged in walking backwards. The movement exercises muscles that are not used in ordinary walking, especially in the back, waist, thighs, knees and lower legs. It is also suggested that walking backwards is akin to a karmic reversal, allowing for corrections of mistakes and sins of the past (Beijing Scene 2003).

Walking backwards seems to fit in the movement associated with grief The art of grieving requires the use of different muscles than we are used to using in our lives, and grief appears as perversely different from what is expected as does an old man walking backwards. Walking backwards allows the strengthening of part of ourselves that we were not aware of or did not have to use. It allows one the ability to look to the past and recall what was, and yet continue to move along. We do not see this walking backwards as a permanent state or gait, nor do we suggest that the bereaved should not ever look ahead and walk in more typical fashion, but what we are suggesting is that grief requires this occasional and periodic walk backwards. As Chodron 1997 wrote:

The path has one very distinct characteristic: it is not pre fabricated. It doesn't already exist ... The path is not Route 66-destination, Los Angeles. It's not as if we can take out a map ... the path is uncharted. It comes into existence moment by moment and at the same time drops away behind us. It's like riding in a train sitting backwards. We can't see where we're headed, only where we've been (143).

Walking backwards implies moving backwards but paradoxically, this is not the case. We are always, already moving forward in life, and walking backwards requires that one move ahead, periodically faced to the past. Therefore, the future, as is always unknown, remains outside of sight, yet the past is necessarily in sight as it glides within vision and continues to recede, as the past is inclined to do. This idea of walking backward might be a helpful one to people who are experiencing grief. It invites the belief that this is their own experience and that others, even professionals, do not have the right to prescribe the 'right' way or offer a map. 
Grief is often described as a process. The word process can imply something with structure, form, sequence, beginning, and end. It can invite people into believing that there is a particular form that needs to take shape. It is a normalizing discourse. Another definition of process, however, that might be more aptly applied to grief is that of process as a 'naturally continuing activity or function' (Agnes and Guralnik 1999), such as breathing. Process does not necessarily connote something with distinct phases and predictable endings. Moving ahead while 'walking backwards' as an activity of living, despite its paradox, is an art that grief is capable of teaching well.

\section{IMPLICATIONS FOR PRACTICE}

\section{The nature of grief and the art of riding waves}

When we are born, we enter into life with few guarantees except for the impermanence of life - our own and others. We enter into a world that is built on this premise and yet a world that in every way rebels against the inevitable. We fight to sustain life, to avoid death, to avoid the pain of loss. Gadamer (1996) suggested that the enigma of health is such that we are only aware of it in its absence. In a similar way, once we have a particular experience of death, loss, and grief, an awareness is brought sharply into our field of vision. When we realize that something is going on and has always been going on, something arrives in our lives and life will never be the same again. There is a loss of naiveté, a new aware ness that was not wanted and was necessarily purchased at a high price. When death and loss arrive, they arrive accompanied by grief. The arrival stays with us, haunts us, wakes us at night, asks questions of us, and needs to be answered and re-answered over time.

In this study, it occurred to us that not only can grief be interpreted hermeneutically, but also that grief itself is a hermeneutic experience. In this regard, perhaps the most appropriate interventions a nurse might offer around grief would be to ask questions about the questions the bereaved are grappling with, and to open the idea that there may be no answers, or more than one answer but that the challenge of grief is about being able to live in the questions. Nurses can support families in their experiences that grief might evolve, recede, and return over time, but that it will never un-arrive.

One person in this study spoke about grief as 'coming in waves' and this offers the image of water, a moving medium that is ever shifting, yet permanent, a medium through which we attempt to understand our lives. Perhaps these waves are moments of arrival, moments of remembrance. When grief is thus uncovered and forefront, there might be times when the experience is too powerful to swim. Are they drowning moments, when one would lose their breath and be unable to sustain a conversation? Are they followed by the need to rest and recuperate? Alternately, are they comfortable moments when the washing over feels natural and rhythmic? Perhaps they are moments when we need someone else to hold us up above water, or perhaps they are moments when we are able to stay afloat and be moved along. Our experiences with waves is such 
that, if you fight them or swim against them, they can take you under and hold you there, but if you move with them following their direction, they are buoyant, natural, and almost predictable. Perhaps the work of helping people with grief is about knowing how to look for waves and knowing how to ride them rather than let them lake you under.

\section{Grief as an uninvited houseguest}

The beliefs uncovered in this research lend themselves to a metaphor of grief as a houseguest that arrives without invitation and remains in such a way that it touches all aspects of one's life, family, relationships, and health. If room is not made for this uninvited houseguest, it has a tendency to take over the house, claiming the bathroom as one tries to get ready for work, sneaking into children's rooms and affecting their lives, sneaking into the bedrooms of partners. Metaphorically, invited or not, grief sneaks in and becomes a part of the family and household. The more efforts are made to keep it out, the more it makes its presence known. If, how ever, room is made for this houseguest, its presence becomes expected at times, its comings and goings are not surprises, its intrusions not unanticipated. In time, its presence even becomes welcomed as something familiar. This houseguest, welcome or not, does come and go over time and changes in appearance, but its very absence and presence serves to sustain a mutable, evolving, sometimes intermittent, but lifelong, relationship with the loss. Grief has intensive, and sometimes unrelenting, elements of suffering and pain, but it also has attributes of comfort, connection, and celebration. Rosenblatt (1996) suggested that grief has a 'sweet, affirming, and to-becherished side ... it can be a link with the best of life, an affirmation of light and joy' (55). Grief is the experience of keeping in relationship with the lost person, who although physically absent, is still profoundly a member of the family. Death does not mean the end of a relationship, but a change in the relationship, 'with new dimensions and possibilities' (Klass, Silverman and Nickman 1996, xix).

\section{Locked doors: metaphors and openings}

Many of the conversations reviewed in the clinical work moved toward a metaphor of doors and locks. 'I've been slamming the door shut on grief I need to unlock the door.' 'I've closed a lot of doors since my son's death.' This idea of grief as something that can be enclosed, locked away, and opened volitionally is interesting. The belief in the safety of locks is a tenuous one. Locks provide superficial deterrence but they are not impenetrable. We cannot lock happiness in or trouble out. Doors to grieving are always being opened, either voluntarily or broken into, but perhaps it is in the nature of how they are opened where nurses can be of assistance.

We were struck with how often metaphors arise in the language of grief. Perhaps, in our living forward, metaphor offers a palpable something in which to carry grief. The word metaphor means to carry beyond, carry over, transfer, or to bear (Hoad 1986; Neufeldt and Guralnik 1988). 'Metaphor is the way language 
carries itself past its own powers to enter new realms' (Hirshfield 1997, 111). Metaphors, how ever, are only as useful as the ways they fit for clients, the ways they carry over, transfer, or bear some relevant meaning or understanding.

Metaphor offers a safety in one sense, in the separation from the person or the experience from something that can stand in stead for and represent themselves or their experiences. A metaphor allows one to move back and forth between letting the metaphor fit and distancing from it. A metaphor fits when we need it, and is inapplicable when it is not useful and in this way, it generates a removed type of understanding or a perspective that allows people to view themselves and their lives from a slightly different angle. Metaphors provide a view of something from a viewpoint of another thing and yet they work to make one feel 'at home'. 'Yes, that is right; that is what it is like; I recognize that.' Paradoxically, a metaphor simultaneously serves to remove us, while at the same time offering us a home in language and understanding.

What is it about grief that seems to invite metaphors perhaps even more than other human experiences? In this study, we encountered and created metaphors of visitors, houseguests, rooms, doors, walking, journeying, waves, and houses. The fit of metaphor to grief might be connected in part to the mystery of grief Attig (1996) described grief as a 'mystery that pervades our human condition ... ultimately, the mysteries remain beyond our grasp and control' (15-16). Metaphors perhaps offer something to grasp, something that can be pictured and understood as a place to rest the mystery of the profound, wordless, faceless experience of suffering. Kirmayer (1989) suggested that suffering makes poets of sufferers, poets who search for metaphors that can somehow capture adequately the pain of the experience. In this regard, the suffering of grief often finds itself in mystery and metaphor.

Nurses in practice might listen to the metaphorical language of clients, finding ways to embrace and even extend a metaphor. Additionally, this research demonstrated how the offerings of metaphors, if taken up by the families as fitting, serve to help families find a home and description for their experiences. Metaphors offer something familiar and recognizable in the context of the unknown of grief.

In Angels and insects A. S. Byatt (1992) offers a story in which the main character, a scientist, finds a fitting metaphor for his own life in the colony of ants that he is observing. He eventually observes 'analogy is a slippery tool ... men are not ants' (100). In thinking about our research and how we can use metaphor to clarify and bring to clarity our thinking and understanding, especially around abstract and complex concepts like grief, it truly seems to be a natural and useful exploration for many families. Still, we must offer the wondering that, at what point, if any, might it be prudent for nurses to remind themselves that 'men are not ants'. Grief is grief, unique and particular, and the experience of it is one that will be, in many ways, absolutely unlike any other encounter held by someone else, and never adequately captured in any metaphor. 


\section{Walking backwards with the bereaved}

Perhaps the work of health professionals is to learn how to best walk backwards at times with bereaved clients, while keeping a careful watch for bumps on the road. When nurses realize that they do not own a map to grieving, they might be willing to become useful traveling companions with families as they walk backwards. Yet, what happens when nurses are unable to walk backward with families? What kinds of shifts in thinking need to happen in order to be able to walk backwards? What happens when families are not able to walk in this way? Do nurses accept this as their own unique gait, or would they offer tentative interventions and questions that explore and invite new ways of walking? What do we risk in believing that one way of walking is more helpful than another way? What other ways of walking (besides facing forward and backwards) might be useful? Perhaps one way of walking that might be useful at the most painful times could be with eyes closed and holding on to the hand of another. Alternately, some might choose to lie down and rest and not to walk at all for a time. Others might need to run from the pain of grief.

'When something hurts in life, we don't usually think of it as our path or as the source of wisdom. In fact, we think that the reason we're on the path is to get rid of this painful feeling. ('When I get to L.A., I won't feel this way anymore.') At that level of wanting to get rid of our feeling, we naively cultivate a subtle aggression against ourselves' (Chodron 1997, 144). However people choose to journey with grief, perhaps it is in this opening of space for the journey where nurses might be most useful.

\section{IMPLICATIONS FOR FUTURE RESEARCH}

Situated in this study is a grounding for the second phase of this research exploring the interventions offered by healthcare professionals to the bereaved and the experiences of clients in seeking assistance in their grief walk. An intervention study affords a closer examination of practices and their place in the diminishment of suffering in grief. As a focus in the second phase of this project, the ideas of internalization and interventions focused on the internalized lost person will be addressed.

\section{SUMMARY}

This study offers that the experience of grief, though universal and undiscriminating, is one that is replete with personal and professional expectations, sanctioning practices, and cultural discourses. In experiences of grief, these influences serve to foster the creation of personally held beliefs about grief, some of which are comforting and healing, and others which seem to contribute to more suffering in the lives of the bereaved.

This research suggests that the work of nurses and other professionals in their contact with the bereaved may be about being able to recognize, invite, and even challenge the beliefs (Wright, Watson and Bell 1996) that are not particularly helpful to, or consistent with, experiences of grief In this meeting of 
beliefs, we offer the idea that the beliefs held by health professionals are pivotal in inviting the bereaved to consider other ways of making room for their grief and the invitation to walk backwards must come from someone who is not afraid to walk alongside.

\section{ACKNOWLEDGEM ENTS}

We gratefully acknowledge the University of Calgary, Faculty of Nursing, and the University of Calgary Research Offices for financial support of this project.

\section{REFERENCES}

Agnes M and DB Guralnik, eds. 1999. Webster's new world college dictionary, 4th edn. New York: Macmillan.

Arnold J. 1995. A reconceptualization of the concept of grief for nursing: A philosophical analysis. Unpublished doctoral dissertation, New York University.

Attig T. 1996. How we grieve: Relearning the world. New York: Oxford University Press.

Averill JR and EP Nunley. 1988. Grief as an emotion and as a disease: a socialconstructionist perspective. Journal of Social Issues 44(3): 79—95.

Becvar DS. 2001. In The presence of grief: Helping family members resolve death, dying, and bereavement issues. New York: Guilford.

Beijing Scene. 2003. Ask Ayi: Walking backwards in Beijing. Beijing Scene 5(10): May 28-June 3. (Retrieved October 22, 2003) http://wwwbeijingscene.com/V051010/ayi/ ayi.htm.

Byatt AS. 1992. Angels and insects. London: Vintage.

Chodron P. 1997. When things fall apart: Heart advice for difficult times. Boston: Shambahala.

Freud S. 1947. Mourning and melancholia. In The standard edition of the complete psychological works of Sigmund Freud, vol. 14. ed. J Strachey, 23758. London: Institute of Psycho-Analysis and the Hogarth Press (Original work published in 1917).

Gadamer HG. 1989. Truth and method, 2nd rev. edn. Trans. J Weinsheimer and DG Marshall. New York: Continuum.

Gadamer HG. 1996. The enigma of health. Stanford, CA: Stanford University Press.

Goodkin K et al. 2001. Physiological effects of bereavement and bereavement support group interventions. In Handbook of bereavement research:

Consequences, coping, and care, eds MS Stroebe and RO Hansson, 405-29. Washington DC: American Psychological Association.

Hirshfield J. 1997. Nine gates: Entering the mind of poetry. New York: HarperCollins. 
Hoad TF, ed. 1986. The Concise Oxford Dictionary of English Ethymology. New York: Oxford University Press.

Jacob SR. 1993. An analysis of the concept of grief. Journal of Advanced Nursing 18(11): 1787-94.

Kaunonen M, M Tarkka, P Laippala and M Paunonen-IImonen. 2000. The impact of supportive telephone call intervention on grief after death of a family member. Cancer Nursing 23(6): 483-91.

Kirmayer U. 1989. Languages of suffering and healing: Alexithymia as a social and cultural process. Transcultural Psychiatric Research Review 24(2): 119-36.

Klass D, PR Silverman and SL Nickman, eds. 1996. Continuing bonds: New understandings of grief. Philadelphia: Taylor \& Francis.

Lewis CS. 1961. A grief observed. New York: Seabury Press.

Maturana HR and FJ Varela. 1992. The tree of knowledge: The biology roots of human understanding, rev. edn. Boston: Shambahala.

Moules NJ and JK Amundson. 1997. Grief- an invitation to inertia: a narrative approach to working with grief. Journal of Family Nursing 3(4): 378-93.

Moules NJ. 1998. Legitimizing grief: Challenging beliefs that constrain. Journal of Family Nursing 4(2): 142-66.

Neimeyer RA. 2001. Reauthoring life narrative: Grief therapy as meaning reconstruction. Israel Journal of Psychiatry and Related Sciences 38(3-4): 171-83.

Neimeyer RA. 2003. Meaning reconstruction and the experience of loss. Psycho-Oncology.

Neufeldt $\mathrm{V}$ and DB Guralnik, eds. 1988. Webster's new world dictionary, 3rd college edn. New York: Simon and Schuster.

Rancour P. 1998. Practice corner: Practice tips from the Arthur G. James Cancer Hospital and Research Center, Columbus $\mathrm{OH}$. Recognizing and treating dysfunctional grief. Oncology Nursing Forum 25(8): 1310-11.

Rosenblatt PC. 1996. Grief that does not end. In Continuing bonds: New understandings of grief, eds D Klass, PR Silverman and SL Nickman, 45-58. Philadelphia: Taylor and Francis.

Rycroft P and A Perlesz. 2001. Speaking the unspeakable: Reclaiming grief and loss in family life. Australian and New Zealand Journal of Family Therapy 22(2): $57-65$.

Sacks AM. 2001. A cross-disciplinary approach to the under standing and treatment of the bereaved. Psychoanalysis and Psychotherapy 18(2): 217-39. 
Schut H, MS Stroebe, J van den Bout and M Terheggen. 2001. The efficacy of bereavement interventions: Determining who benefits. In Handbook of bereavement research: Consequences, coping, and care, eds MS Stroebe and RO Hansson, 405-29. Washington, DC: American Psychological Association.

Sharpnack JD. 2001. The efficacy of group bereavement interventions: An integrative review of the research literature. Dissertation Abstracts International: The Sciences and Engineering 61(12B): 671.

Silverman PR and D Klass. 1996. Introduction: What's the problem? In Continuing bonds: New understandings of grief, eds D Klass, PR Silverman and SL Nickman, 45-58. Philadelphia: Taylor \& Francis.

Solari-Twadell PA, S Schmidt Bunkers, CE Wang and D Snyde. 1995. The pinwheel model of bereavement. Image: The Journal of Nursing Scholarship 27(4): 323-26.

White M. 1989. Saying hullo again: the incorporation of the lost relationship in the resolution of grief. In Selected papers, ed. M White, 5-28. Adelaide, Australia: Dulwich Centre.

Wortman CB and RC Silver. 2001. The myths of coping and loss revisited. In Handbook of bereavement research: Consequences, coping, and care, eds MS Stroebe and RO Hansson, 405-29. Washington, DC: American Psycho logical Association.

Wright LM, WL Watson and J M Bell. 1996. Beliefs: The heart of healing in families and illness. New York: Basic Books. 